\title{
Oral non Squamous Cell Malignant Tumors in an Iranian Population: a 43 year Evaluation
}

\author{
Nooshin Mohtasham¹, Nasrollah Saghravanian', Maryam Goli², Hamideh \\ Kadeh $^{3 *}$
}

\begin{abstract}
Background: The prevalence of non-squamous cell malignant tumors of the oral cavity has not been evaluated in Iran extensively. The aim of this study was to evaluate epidemiological aspects of the oral malignancies with non-squamous cell origin during a 43-year period in the Faculty of Dentistry, Mashhad University of Medical Sciences, Iran. Materials and Methods: In this retrospective study, the records of all patients referred to dental school of Mashhad university of medical sciences in northeast of Iran, during the period 1971-2013 were evaluated. All confirmed samples of oral non squamous cell malignant tumors were included in this study. Demographic information including age, gender and location of the lesions were extracted from patient's records. Data were analyzed using SPSS statistical soft ware, Chi-square and Fisher's exact tests. Results: Among 11,126 patients, $188(1.68 \%)$ non squamous cell malignant tumors were found, with mean age of 39.9 years ranging from 2 to 92 years. The most common tumors were mucoepidermoid carcinoma (33 cases) and lymphoma (32 cases). Non squamous cell malignant tumors occurred almost equally in men (94 cases) and women (93 cases). Most (134 cases) of them were located peripherally with high frequency in salivary glands ( 89 cases) and 52 cases were centrally with high frequency in the mandible ( 38 cases). Conclusions: More findings in this survey were similar to those reported from other studies with differences in some cases; it may be due to variation in the sample size, geographic and racial differences in tumors.
\end{abstract}

Keywords: Non squamous cell malignant tumor - oral cavity - epidemiology - Iran

Asian Pac J Cancer Prev, 16 (18), 8215-8220

\section{Introduction}

Cancer, a serious problem of public health, is one of the five major causes of death all over the world (Formosa et al., 2015). Head and neck malignancies, especially oral cavity, account for $2.5 \%$ of all cancers. During 1973-2003, there were 10,432 cases of oral cancer among people over 20 years in the United States (Rodu and Cole, 2007; Shenoi et al., 2012).

Oral cancer mostly occurs in middle-aged and older people and is more common in male (Zarei et al., 2007; Mahmoudi et al., 2015); although it has been reported that incidence of the head and neck cancer has increased in women over the past. Based on tissue of origin, malignancies of the oral cavity and its surrounding tissues can be divided into five groups: epithelial lesions, salivary gland, soft tissue, hematologic, and hard tissue lesions (Aminzadeh et al., 2013).

Different environmental factors may cause various manifestations of these malignancies in the oral cavity. Prevalence of the oral cancer varies in different countries; also it may change with age, gender, race, and geographical location (Delavarian et al., 2009). Approximately, $75 \%$ of the people with oral cancer are in the developing countries, particularly Southeast Asia and the Indian subcontinent, where the oral cavity is often the first or second most common location for malignancies. Iran is the second largest country in the Middle East with an approximate population of seventy million people (Zarei et al., 2007), which in 2012 the prevalence of lip and oral cancers has been reported 2.2 in men and 1.8 in females in Iran (Razavi et al., 2015). Also according to the data released by the Iranian Ministry of Health in 2003, oral cancer is one of the ten most common cancers in females in Khorasan Province (Northeast of Iran) (Delavarian et al., 2009).

According to the importance of the epidemiological studies and a lack of information about the head and neck cancers in Iran (Rad et al., 2010), the aim of the present study was to examine epidemiological aspects of different oral malignancies with a non-squamous cell of origin during a 43-year period in Faculty of Dentistry, Mashhad University of Medical Sciences, that is one of the largest referral centers for the patients in the northeast of the country, including North Khorasan, Razavi Khorasan and 
South Khorasan provinces. Comparison was then made with other countries.

\section{Materials and Methods}

In this retrospective study, all records in the Department of Oral and maxillofacial Pathology, Dental School, Mashhad University of Medical Sciences, Iran were investigated between 1971 and 2013. All of oral and maxillofacial biopsies related to non squamous cell malignant tumors were separated and their diagnosis was confirmed by microscopic reevaluation. Then categorized into five general categories: salivary gland carcinoma (cancers with salivary gland tissue origin), soft tissue (cancers related to soft tissue and mesenchymal tissue origin), hard tissue (cancers with bone tissue origin), hematologic (cancers with hematopoietic cells origin) and odontogenic (cancers with odontogenic origin) malignancy. Clinicopathological data including age, gender, primary site and histologic type of the lesions were collected from patient records. The cases with incomplete demographic information and the cases which its histopathological diagnosis could not be verified were excluded from this study.

Data were analyzed using SPSS software (SPSS Inc, Chicago, IL), Chi- square and Fisher's exact tests. P-values less than 0.05 were considered statistically significant.

\section{Results}

In this study between 1971 and 2013 (43-year period), a total number of 11126 cases of oral and maxillofacial lesion were investigated, that $188(1.68 \%)$ of them related to non squamous cell malignant tumors. Cancers of the salivary gland were the most common non squamous cell malignant tumors that representing $100(53 \%)$ of the cases, followed by malignancies of hematologic with 41 (21.9\%) cases, hard tissue with 25 (13.4\%), soft tissue with $20(10.7 \%)$ and odontogenic with $2(1 \%)$ of cases respectively. The mean age of the patients with non squamous cell malignant tumors, was 39.85 years ranging from 2 to 92 years, also were more common in fifth decade of life. According to Chi-square test, there was significant correlation between age and salivary, hematologic and hard tissue malignant tumors $(\mathrm{p}<0.001)$ (Table 1$)$

These tumors were occurred almost equally in men (94 cases) and women (93 cases). According to Fisher's exact test there was no significant correlation between gender and types of non squamous cell malignant tumors $(\mathrm{p}=0.657)$. (Table 2$)$

Most (134 cases) of the non squamous cell malignant tumors were located peripherally with high frequency ( 80 cases) in minor salivary glands. Also $52(28.1 \%)$ of non squamous cell malignant tumors were centrally which $38(73 \%)$ of them were in the mandible and $14(27 \%)$ were in the maxilla. Chi-square test showed a significant relationship between location and salivary, hematologic and soft tissue malignant tumors $(\mathrm{p}<0.001)$. (Table 3 )

Other characteristics of non squamous cell malignant tumors separately depending on the type of malignancy that evaluated in the present study are as follows (Table 4):

\section{Salivary glands malignant tumors}

The most prevalent histologic type of these tumors were mucoepidermoid carcinoma that presenting 33 (17.6\%) of all the cases, followed by adenoid cystic carcinoma $28(15 \%)$ and salivary duct carcinoma had lowest prevalence (1\%). Malignant tumors of the salivary

Table 1. Age Distribution of Non-Squamous Cell Malignant Tumors

\begin{tabular}{|c|c|c|c|c|c|c|}
\hline \multirow[t]{3}{*}{ Age } & \multicolumn{5}{|c|}{ Type Of Malignancy } & \multirow{3}{*}{$\begin{array}{c}\text { Total } \\
\mathrm{N}\end{array}$} \\
\hline & Salivary & Hematologic & Soft Tissue & Hard Tissue & $\overline{\text { Odontogenic }}$ & \\
\hline & $\mathrm{N}$ & $\mathrm{N}$ & $\mathrm{N}$ & $\mathrm{N}$ & $\mathrm{N}$ & \\
\hline $0-9$ & 1 & 10 & 1 & 1 & 0 & 13 \\
\hline $10-19$ & 7 & 5 & 3 & 12 & 0 & 27 \\
\hline $20-29$ & 15 & 3 & 2 & 5 & 0 & 25 \\
\hline $30-39$ & 15 & 4 & 5 & 1 & 0 & 25 \\
\hline $40-49$ & 23 & 8 & 4 & 3 & 1 & 39 \\
\hline $50-59$ & 22 & 4 & 2 & 0 & 0 & 28 \\
\hline $60-69$ & 9 & 3 & 0 & 2 & 0 & 14 \\
\hline$>70$ & 6 & 2 & 1 & 1 & 1 & 11 \\
\hline Total & 98 & 39 & 18 & 25 & 2 & 182 \\
\hline p-Value & $<0.001$ & $<0.001$ & 0.756 & $<0.001$ & - & \\
\hline
\end{tabular}

*In 6 cases, age of patients was not recorded in the patient's record. (2 cases of salivary gland, 2 cases of hematologic and 2 cases of soft tissue malignancies)

Table 2. Gender Distribution of Non-Squamous Cell Malignant Tumors

\begin{tabular}{lccccc}
\hline Gender & & & Type of malignancy & & \multicolumn{2}{c}{ Total } \\
& Salivary & Hematologic & Soft tissue & Hard tissue & Odontogenic \\
& $\mathrm{N}$ & $\mathrm{N}$ & $\mathrm{N}$ & $\mathrm{N}$ & $\mathrm{N}$ \\
\hline Female & 51 & 22 & 7 & 13 & 0 \\
Male & 49 & 19 & 12 & 12 & 2 \\
Total & 100 & 41 & 19 & 25 & 2 \\
p-Value & 0.657 & 0.657 & 0.657 & 0.657 & 187 \\
\hline
\end{tabular}

*In one case of soft tissue sarcoma, gender was not recorded in the patient's record 
Oral Non-Squamous Cell Malignant Tumors in an Iranian Population: a 43 year Evaluation

glands were more common in the fifth and sixth decades of the life. The distribution of these tumors was slightly more prevalent in female (51 cases), only polymorphous low grade adenocarcinoma and adenoid cystic carcinoma were more in males.

\section{Hematologic malignant tumors}

Lymphoma constituted $32(78 \%)$ cases of the hematologic malignancies. These tumors occurred more frequently in first decade of life and were observed in women ( 22 cases) than in men (19 cases) but lymphoma

Table 3. Location Distribution of non Squamous Cell Malignant Tumors

\begin{tabular}{|c|c|c|c|c|c|c|}
\hline \multirow[t]{2}{*}{ Location } & \multicolumn{5}{|c|}{ Type of malignancy } & \multirow{2}{*}{$\begin{array}{c}\text { Total } \\
\mathrm{N}\end{array}$} \\
\hline & $\begin{array}{c}\text { Salivary } \\
\mathrm{N}\end{array}$ & $\begin{array}{c}\text { Hematologic } \\
\mathrm{N}\end{array}$ & $\begin{array}{c}\text { Soft tissue } \\
\mathrm{N}\end{array}$ & $\begin{array}{c}\text { Hard tissue } \\
\text { N }\end{array}$ & $\begin{array}{c}\text { Odontogenic } \\
\mathrm{N}\end{array}$ & \\
\hline Buccal mucosa & 0 & 5 & 2 & 0 & 0 & 7 \\
\hline Gingiva & 0 & 12 & 8 & 0 & 0 & 20 \\
\hline Floor of mouth & 0 & 1 & 0 & 0 & 0 & 1 \\
\hline Palate & 0 & 0 & 1 & 0 & 0 & 1 \\
\hline Vestibule & 0 & 4 & 2 & 0 & 0 & 6 \\
\hline Salivary glands & 89 & 0 & 0 & 0 & 0 & 89 \\
\hline Sinuses & 6 & 2 & 2 & 0 & 0 & 10 \\
\hline Jaws bone & 4 & 17 & 4 & 25 & 2 & 52 \\
\hline Total & 99 & 41 & 19 & 25 & 2 & 186 \\
\hline p-Value & $<0.001$ & $<0.001$ & $<0.001$ & - & - & \\
\hline
\end{tabular}

In one case of soft tissue sarcoma and one case of salivary gland malignancy, location was not recorded in the patient's record

Table 4. Distribution of 188 Non-Squamous Cell Malignant Tumors According to Age and Gender

\begin{tabular}{|c|c|c|c|c|c|c|c|c|c|c|c|c|}
\hline \multirow{3}{*}{\multicolumn{2}{|c|}{ Type of lesion }} & \multirow{3}{*}{ No. } & \multicolumn{8}{|c|}{ Age groups } & \multicolumn{2}{|c|}{ gender } \\
\hline & & & \multirow{2}{*}{$\frac{0-9}{\mathrm{~N}}$} & \multirow{2}{*}{$\frac{10-19}{\mathrm{~N}}$} & \multirow{2}{*}{$\frac{20-29}{\mathrm{~N}}$} & \multirow{2}{*}{$\frac{30-39}{\mathrm{~N}}$} & \multirow{2}{*}{$\frac{40-49}{\mathrm{~N}}$} & \multirow{2}{*}{$\frac{50-59}{\mathrm{~N}}$} & \multirow{2}{*}{$\frac{60-69}{\mathrm{~N}}$} & \multirow{2}{*}{$\frac{>70}{N}$} & \multirow{2}{*}{$\frac{\text { female }}{\mathrm{N}}$} & \multirow{2}{*}{$\frac{\text { male }}{\mathrm{N}}$} \\
\hline & & & & & & & & & & & & \\
\hline \multirow{7}{*}{ Salivary } & MEC & 33 & 1 & 4 & 8 & 6 & 6 & 4 & 3 & 1 & 18 & 15 \\
\hline & ADCC & 28 & 0 & 1 & 3 & 5 & 7 & 5 & 2 & 3 & 12 & 16 \\
\hline & AC NOS & 15 & 0 & 0 & 0 & 0 & 7 & 4 & 3 & 1 & 9 & 6 \\
\hline & M.P.A & 11 & 0 & 1 & 2 & 3 & 2 & 2 & 0 & 1 & 7 & 4 \\
\hline & SDC & 1 & 0 & 0 & 0 & 0 & 1 & 0 & 0 & 0 & 1 & 0 \\
\hline & $\mathrm{ACC}$ & 4 & 0 & 1 & 0 & 1 & 0 & 2 & 0 & 0 & 2 & 2 \\
\hline & PLGA & 8 & 0 & 0 & 2 & 0 & 0 & 5 & 1 & 0 & 2 & 6 \\
\hline \multirow{5}{*}{ Hematologic } & Lymphoma & 32 & 9 & 4 & 3 & 3 & 7 & 2 & 2 & 2 & 16 & 16 \\
\hline & Multiple myeloma & 5 & 0 & 0 & 0 & 1 & 1 & 1 & 1 & 0 & 5 & 0 \\
\hline & leukemia & 2 & 0 & 1 & 0 & 0 & 0 & 0 & 0 & 0 & 1 & 1 \\
\hline & Lang.cell.dis & 1 & 1 & 0 & 0 & 0 & 0 & 0 & 0 & 0 & 0 & 1 \\
\hline & angiosarcoma & 1 & 0 & 0 & 0 & 0 & 0 & 1 & 0 & 0 & 0 & 1 \\
\hline \multirow{7}{*}{ Soft tissue } & Undiff.sarcoma & 8 & 0 & 1 & 0 & 3 & 2 & 0 & 0 & 0 & 3 & 4 \\
\hline & Kaposi sarcoma & 1 & 0 & 0 & 0 & 0 & 0 & 0 & 0 & 1 & 0 & 1 \\
\hline & fibrosarcoma & 4 & 0 & 1 & 0 & 1 & 1 & 1 & 0 & 0 & 2 & 2 \\
\hline & $\mathrm{MFH}$ & 2 & 0 & 0 & 0 & 0 & 1 & 1 & 0 & 0 & 1 & 1 \\
\hline & Leiomyo sarcoma & 1 & 0 & 1 & 0 & 0 & 0 & 0 & 0 & 0 & 0 & 1 \\
\hline & $\begin{array}{c}\text { Rhabdomyo } \\
\text { sarcoma }\end{array}$ & 2 & 1 & 0 & 1 & 0 & 0 & 0 & 0 & 0 & 1 & 1 \\
\hline & MPNST & 2 & 0 & 0 & 1 & 1 & 0 & 0 & 0 & 0 & 0 & 2 \\
\hline \multirow{2}{*}{ Hard tissue } & osteosarcoma & 21 & 1 & 11 & 5 & 1 & 1 & 0 & 1 & 1 & 10 & 11 \\
\hline & chondrosarcoma & 4 & 0 & 1 & 0 & 0 & 2 & 0 & 1 & 0 & 3 & 1 \\
\hline Odontogenic & $\begin{array}{c}\text { Malignant. } \\
\text { ameloblastoma }\end{array}$ & 2 & 0 & 0 & 0 & 0 & 1 & 0 & 0 & 1 & 0 & 2 \\
\hline \multicolumn{2}{|r|}{ Total } & 188 & 13 & 27 & 25 & 25 & 39 & 28 & 14 & 11 & 93 & 94 \\
\hline
\end{tabular}

MEC: Mucoepidermoid carcinoma, ADCC: Adenoid cystic carcinoma, AC NOS: Adenocarcinoma not otherwise specified, M.P.A: Metastasizing pleomorphic adenoma, SDC: Salivary duct carcinoma, ACC: Acinic cell carcinoma, PLGA: Polymorphous low-garde adenocarcinoma, Lang.cell. dis: langerhans cell disease, MFH: Malignant fibrous histiocytoma, MPNST: Malignant peripheral nerve sheath tumor 
with equal frequency (16 cases) was seen in male and females. Most of the hematologic malignancies were located in jaws bone (17 cases), followed by gingiva (12 cases).

\section{Soft tissue malignant tumors}

The most common malignant tumor in these group was undifferentiated sarcoma that presenting $8(40 \%)$ of all cases, followed by fibrosarcoma (20\%). The majority of soft tissue sarcoma affected gingiva ( 8 cases) and palate with prevalence of one case was lowest common location. There was a predilection for the male with 12 cases and soft tissue sarcomas most occurred in forth decade of life.

\section{Hard tissue malignant tumors}

Osteosarcoma and chondrosarcoma of the jaws are 2 types of the hard tissue malignant tumors that occur in the oral cavity and in this study constituted $84 \%$ and $16 \%$ of cases respectively. Most of the patients with hard tissue malignant tumors were more common in the second decade of the life and was seen equally in men (12 cases) and women (13 cases) almost, but chondrosarcoma was seen three times higher in women. The most common site of hard tissue malignant tumors was mandible (16 cases).

\section{Odontogenic malignant tumors}

There were only two cases of the odontogenic malignant tumors in the present study that was diagnosed as malignant ameloblastoma and related to one patient. This malignancy was observed in a man in fifth decade of life and its recurrence occurred in seventh decade.

\section{Discussion}

The prevalence of non-squamous cell malignant tumors of the oral cavity has not been evaluated in Iran extensively (Zarei et al., 2007). So this study evaluated the frequency and other characteristics of these tumors over a 43-year period in the Faculty of Dentistry, Mashhad University of Medical Sciences, Iran.

Among the total 188 malignant tumors that examined between 1971 and 2013, 100 cases (53\%) had salivary gland lesions, 41 cases $(21.9 \%)$ hematological lesions, 25 cases $(13.4 \%)$ hard tissue lesions, 20 cases $(10.7 \%)$ soft tissue lesions, and 2 cases (1\%) odontogenic lesions.

Similarly to our study, in other studies among non squamous cell malignant tumors, salivary lesions was the most frequent malignancy, followed by hematologic - lymphoid (lymphoma) malignant lesions (Daley and Darling, 2003; Zarei et al., 2007; Aminzadeh et al., 2013; Aydil et al., 2014).

In Rahrotaban et al. study consistent with the present study, Mucoepidermoid carcinoma was reported as the most common malignant tumor of the salivary glands (Rahrotaban et al., 2010). However, some other studies reported adenoid cystic carcinoma as the most frequent malignant tumor of the salivary glands (Saki and Nikakhlagh, 2004; Kara et al., 2010). On the other hand, Pardis et al. reported a similar prevalence of Mucoepidermoid carcinoma and adenoid cystic carcinoma in their study (Pardis et al., 2012).
In the group of hematologic malignant tumors, the highest frequency was associated with lymphoma, which is similar to earlier findings (Daley and Darling, 2003; Zarei et al., 2007; Aydil et al., 2014). However, in one report $3 \%$ of the total 66 malignancies included lymphoma with highest prevalence among the males and mean age of 45 years (Aydil et al., 2014); whereas, 17.1\% of 188 cases in this study included lymphoma, with mean age of 33.63 years and no significant gender difference. These may be due to variation in sample size, geographic and racial differences in tumors.

In study of Luna et al. in Mexico was reported one case of angiosarcoma between 113 pathology samples diagnosed with lip cancer during 11 years (Luna-Ortiz et al., 2004). Similarly, present study reported one case of angiosarcoma among 188 cases in a 43-year period.

Le Treut et al. (2013) reported two children with rhabdomyosarcoma of stensen duct (Le Treut et al., 2013) which is similar to our study; but in the present study 2 rhabdomyosarcoma cases observed in the gingiva and jaw among 188 samples during 43 years.

Inconsistence with this study, in Aminzadeh et al. (2013) study has been reported a similar frequency for soft tissue and hard tissue malignant lesions (Aminzadeh et al., 2013) whereas, this study reported the frequency of hard and soft tissues malignancies as $13.4 \%$ and $10.7 \%$, respectively. In Ansari et al. study, over a period of 13 years, malignant fibrous histiocytoma had minimum frequency in soft tissue malignant tumors (Ansari, 2002); whereas, the minimum frequency in our study associated with Kaposi's sarcoma and leiomyosarcoma that presenting one case. This difference is probably related to the sample size in each study and geographic and racial differences.

Other studies on hard tissue malignant tumors also reported osteosarcoma as the most common malignancy of hard tissue (Bennetta et al., 2000; Daley and Darling, 2003), which is consistent with the findings of our study. Another study in India showed low prevalence of chondrosarcoma with one case in maxilla (Gawande et al., 2014). Our study showed four cases with chondrosarcoma, one in maxilla and three in mandible.

The only odontogenic malignant tumor reported in this study was malignant ameloblastoma with the frequency of two cases. It was also reported by Rizzitelli et al. that in their study malignant ameloblastoma accounts for 1.6-2.2\% of odontogenic tumors(Rizzitelli et al., 2015).

In this study, the frequency of non-squamous cell malignant tumors in males and females was almost equal. Among the five groups of malignant tumors, soft tissue and odontogenic malignancies were more common in males and salivary, hematologic and hard tissue malignancies in females.

Delavarian et al. reported that of all oral malignancy cases $48 \%$ were male and $52 \%$ were female, also they noted one of the reasons for higher frequency of the oral cancers in female can be due to higher referral of them to treatment centers. (Delavarian et al., 2009); whereas, other studies reported a greater frequency of malignant lesions in males (Ansari, 2002; Aminzadeh et al., 2013; Aydil et al., 2014). 
Inconsistent with ours, Saki et al. (2004) in Ahvaz (Iran) and Kara et al. (2010) in Turkish reported a greater frequency of salivary malignant tumors in men (Saki and Nikakhlagh, 2004; Kara et al., 2010). But in Rahrotaban et al. study the frequency of salivary malignant tumors was similar in both males and females (Rahrotaban et al., 2010).

Similarly, Khalili et al. and Le Treut et al. reported that soft tissue sarcomas were more common in males (Khalili et al., 2012; Le Treut et al., 2013)and in another study in UK found more prevalent of osteosarcoma in women (Bennetta et al., 2000), which are consistent with our findings. In Rizzitelli et al. (2015) study found a greater frequency of malignant ameloblastoma in males (Rizzitelli et al., 2015). Also both odontogenic malignant tumors which observed in the present study were also male.

Regarding location, findings of this study showed 134 cases of peripheral lesions ( $71.9 \%$ of total malignancies) versus 52 cases of central lesions $(28.1 \%$ of total malignancies). In a study with smaller sample size, Delavarian reported 41 peripheral and 3 central cases of oral cancer, respectively (Delavarian et al., 2009).

In the present study, the highest rate of salivary malignancies related to minor salivary glands; whereas, other studies reported the highest rate of these lesions in the major salivary glands, particularly parotid gland (Saki and Nikakhlagh, 2004; Kara et al., 2010; Rahrotaban et al., 2010).

Our findings regarding malignant hard tissue lesions were similar to Junior et al. study that evaluated clinicopathological analysis of the twenty five head and neck osteosarcoma and reported a greater frequency of osteosarcoma in the mandible (Junior et al., 2003).

In this study, the mean age of the patients was 39.85 years with ranging from 2 to 92 years. The Most of the patients were in the 40-50 age group and the lowest number of the patients were in the age group above 70 years. The reason of the low frequency of these malignancies in this age group is probably due to an increase in deaths in this period for reasons other than malignancy. Ansari reported the mean age of patients with maxillofacial malignant tumors as 43.5 years ranging from 3 to 92 years (Ansari, 2002), which is almost similar to our results. Other studies in Iran reported the mean ages of 53.53 and 54 years in oral malignancies (Delavarian et al., 2009; Aminzadeh et al., 2013).

In our study the mean age of patients with salivary malignant tumors was estimated 45.42 years, ranging from 12 to 80 years. Kara et al. (2010) in Turkish reported the mean age of the patients with salivary gland tumors as 41.97 and ranging from 16-80 years (Kara et al., 2010). Whereas, Saki et al. in Iran obtained the mean age of about 50 years ranging from 24-76 years in patients with tumors of the submandibular gland. (Saki and Nikakhlagh, 2004)

The mean age of patients with hard tissue malignant tumors in this study was 29.28 years, which is similar to Junior et al. study that examined clinicopathological analysis of the twenty five head and neck osteosarcoma (Junior et al., 2003). In contrast, Bennett et al. (2000) in UK reported the mean age of the patients with osteosarcoma as 36.9 years during 30 year evaluation
(Bennetta et al., 2000).

\section{References}

Aminzadeh A, Motaghi A, Mohammadi E (2013). Epidemiologic study of oral and paraoral malignancies in one cancer referral center in Isfahan during a 5-year period. J Isfahan Dental School, 8, 560-66.

Ansari M (2002). A 13 years statistical evaluation on maxillofacial malignant tumors in Hamedan. J Dental Med, 15, 103-8.

Aydil U, Kizıl Y, Bakkal FK, et al (2014). Neoplasms of the Hard Palate. J Oral Maxillofacial Surgery, 72, 619-26.

Bennetta J, Thomasa G, Evansb A, et al (2000). Osteosarcoma of the jaws: a 30-year retrospective review. Oral Surg Oral Med Oral Pathol Oral Radiol Endod, 90, 323-33.

Daley T, Darling M (2003). Nonsquamous cell malignant tumours of the oral cavity: an overview.J (Canadian Dental Association), 69, 577-82.

Delavarian Z, Pakfetrat A, Mahmoudi S (2009). Five years retrospective study of oral and maxillofacial malignancies in patients referred to oral medicine department of mashhad dental school-Iran. J Mash Dent Sch, 33, 129-38.

Formosa J, Jenner R, Nguyen-Thi M-D, et al (2015). Awareness and knowledge of oral cancer and potentially malignant oral disorders among dental patients in far north queensland, Australia. Asian Pac J Cancer Prev, 16, 4429.

Gawande M, Swastika N, Chaudhary M, et al (2014). Chondrosarcoma of maxilla. J Oral Maxillofacial Pathol, 18, 423.

Junior AT, de Abreu Alves F, Pinto CAL, et al (2003). Clinicopathological and immunohistochemical analysis of twenty-five head and neck osteosarcomas. Oral oncol, 39, 521-30.

Kara MI, Goze F, Ezirganli S, et al (2010). Neoplasms of the salivary glands in a Turkish adult population. Med Oral Patol Oral Cir Bucal, 15, 880-5.

Khalili M, Eshghyar N, Ensani F, Shakib PA (2012). Synovial sarcoma of the mandible. J Res Med Sci, 17, 1082.

Le Treut C, Rome A, Cassagneau P, et al (2013). Rhabdomyosarcoma of Stensen's Duct in Children. Ann Otol Rhinol Laryngol, 122, 382-5.

Luna-Ortiz K, Güemes-Meza An, Villavicencio-Valencia V, et al (2004). Lip cancer experience in Mexico. An 11-year retrospective study. Oral oncol, 40, 992-9.

Mahmoudi FP-A, Torab A, Piri R, et al (2015). Epidemiology of oral cancer in Iran: a systematic review. Asian Pac J Cancer Prev, 16, 5427-32.

Pardis S, Karandish M, Lavaee-Mashadi F (2012). The clinicopothologic study of benign and malignant lesions of salivary glands in patients attending Shiraz dental school in 15 years. Zahedan J Rese Med Sci, 13, 52-5.

Rad M, Chamani G, Zarei M, et al (2010). Epidemiological aspects of head and neck cancers in a group of iranian population. J Dent, 10, 50-6.

Rahrotaban S, Masoomi P, Moradi M, et al (2010). Frequency of salivary gland tumors in two referral center of qazvin university of medical sciences from 1999 to 2009. J Res Dental Sci, 7, 1-5.

Razavi SM, Tahani B, Nouri S, et al (2015). Oral cancer knowledge and practice among dental patients and their attitude towards tobacco cessation in Iran. Asian Pac J Cancer Prev, 16, 5439.

Rizzitelli A, Smoll NR, Chae MP, et al (2015). Incidence and overall survival of malignant ameloblastoma. PloS one, 10, 117789.

Rodu B, Cole P (2007). Oral cavity and pharynx-throat cancer in the United States, 1973-2003. Oral Surg Oral MedOral 
Pathol Oral Radiol Endodontol, 104, 653-8.

Saki N, Nikakhlagh S (2004). overview of a 15 year experience with benign and malignant tumors of submandibular gland. Iran J Otorhinol, 36, 39-43.

Shenoi R, Devrukhkar V, Sharma B, et al (2012). Demographic and clinical profile of oral squamous cell carcinoma patients: a retrospective study. Indian J Cancer, 49, 21.

Zarei M, Chamani G, Hashemipoor M, et al (2007). An epidemiologic study of oral and pharyngeal nonsquamous cell malignant tumors in kerman province, Iran. J Dent Tehran University Med Sci, 4, 37-42. 